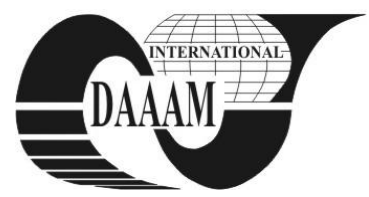

Annals of DAAAM for 2011 \& Proceedings of the 22nd International DAAAM Symposium, Volume 22, No. 1, ISSN 1726-9679 ISBN 978-3-901509-83-4, Editor B. Katalinic, Published by DAAAM International, Vienna, Austria, EU, 2011 Make Harmony between Technology and Nature, and Your Mind will Fly Free as a Bird Annals \& Proceedings of DAAAM International 2011

\title{
FORM DEVELOPING PROCESS FOR STORAGE FURNITURE DESIGN
}

\author{
MUSCU, I[oan] \& OLARESCU, A[lin]
}

\begin{abstract}
The paper represents a contribution at the creation and form developing process for storage furniture design. The steps of the process are defined and their content is presented. The role of Steps 4 and 5 is predominantly highlighted, by a more detailed visual and punctual presentation of the direction of the analysis and the work methods

Key words: concept, form, content, methods of drawing representation, functional, expressive
\end{abstract}

\section{INTRODUCTION}

The design activity, understood as an intentional activity, completes and rounds off, as a specific part, the vast domain of human creation. The process of this activity is defined as a general process of problem resolving through the responsibility of creative teams (Burdek \& Bernhard, 1975). Its finality refers to the voicing of new ideas through research and experiment, engineering design and technologic processing. As it is ensuing from the study of creation methodologies in the modern and contemporary era, their main characteristic is represented by the use of creativity methods, useful for generating and developing new ideas and products (Norbury, 2000). Our proposal seeks to place the methodological accent upon the steps marking the transfer of theoretical expressions into practical visualizations of the form development, as well as the definition of the construction and the composing elements belonging to the product (Pearce \& Pearce, 1980). Within the process these are presented as Step 4 - The working out of the concept, and Step 5 - Development of the concept. Within the frame of a creation theme referring to a product or a product system development, we propose a method of developing the form by using modeling algorithms which are supported by a functional analysis and which are able to become a flexible instrument for developing the concept variants (Fig. 5), which can thus be analyzed and evaluated by using objective criteria (Itten, 1975; Design \& Imitation, 2004; Norbury, 2000).

\section{SUBSTANCE OF RESEARCH}

2.1 Defining a form creation methodology for storage furniture as a creation and design process with identifiable steps

The methodology, as a process of research, concept seeking, market launching of new consumption goods, unveils itself as a systematic process with specific steps or phases.

This process means a development of activities and actions with a specific content which is triggered by the defining of the research and design theme. The analysis of the whole process leads to the grouping of these actions, based upon the principle of research orientation and content similitude presented in Fig.1. Its formulation as a linear, structurally sound schematic process, is a general presentation modality used in research and design, but its execution as a specific and determining activity means a ramified structure in which the relations may be not only directly-progressive but also reactive, through coming back and reformulating previous problems.

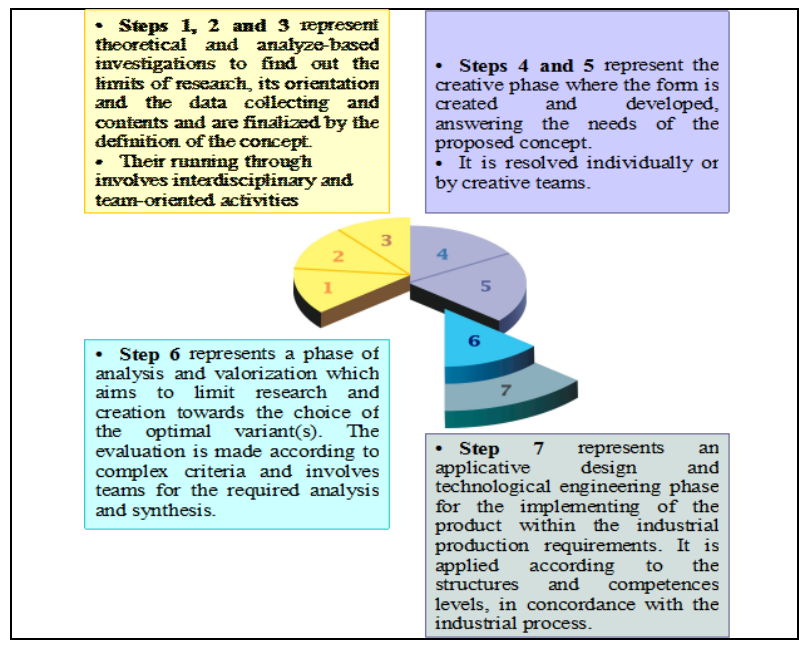

Fig.1. The general character and the steps orientation

Figure 2.a. presents the content of the steps where we have highlighted the direct determinations between them, as well as the reversible moments which appear in the execution of the process. The diagram in Figure 2.b highlights the triggering moments and the overlapping of the actions.

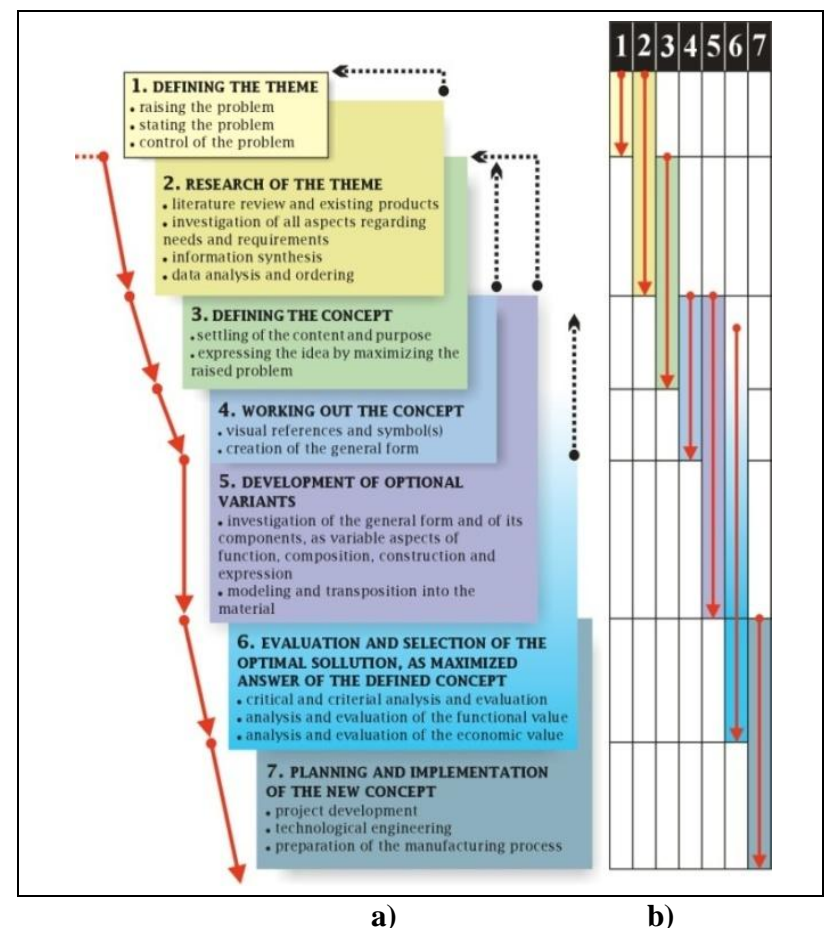

Fig. 2. a) The steps of the process and their interdependence; b) The diagram of the process steps 


\subsection{The storage furniture concept creation and development} becomes operational

We propose a synthetic-visual and content-oriented explanation of the applied actions resulted from the steps concerning the creation and development of the concept (Step 4 and 5), which are grouped as proper phases of the creation of furniture form, by the orientation of research and by specific characteristics. The definition of the concept, as a result of carrying out the research and analysis referring to the proposed theme is: A furniture object with modular and structural transformation capacities, meant for a dining-room connected to the living room.

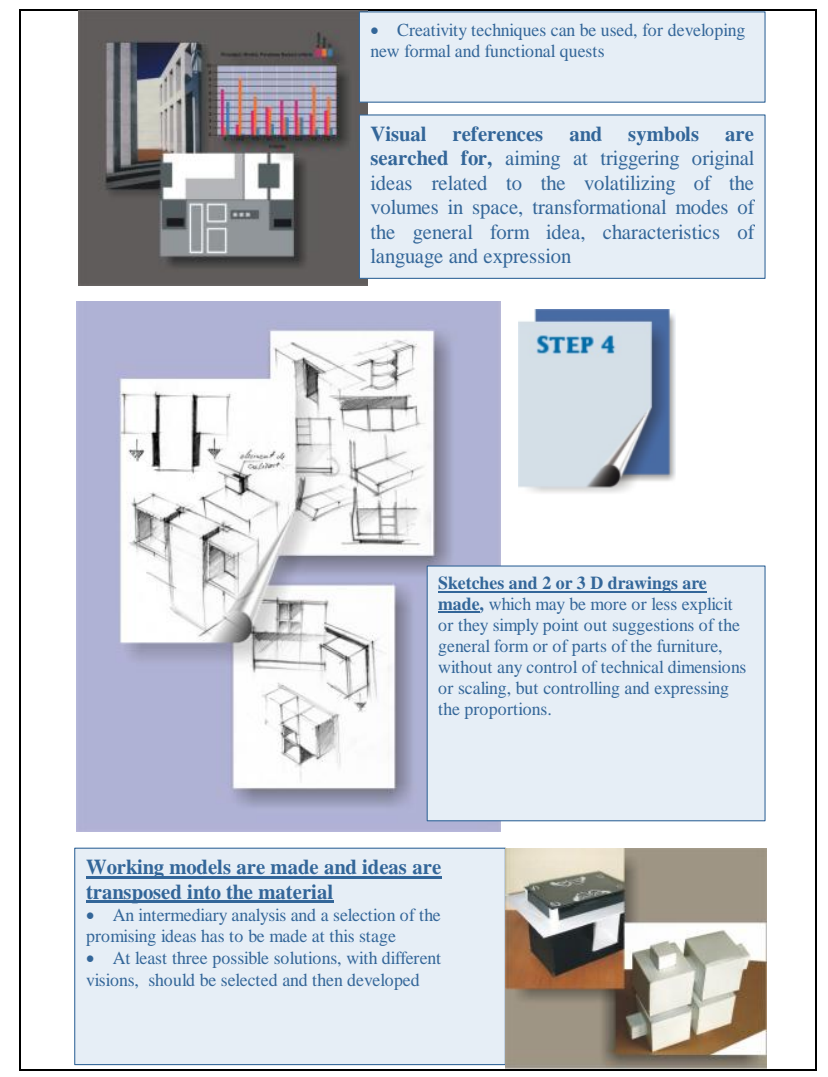

Fig. 3. Step 4 - Working up the concept

The possibilities of approaching and developing the creation of form are presented in Fig. 3 and 4, where research directions and specific work methods are synthetically highlighted (Pearce \& Pearce, 1980; Burdek \& Bernhard, 1975).

\section{CONCLUSIONS}

The triggering moment of such a process can be an incipient idea defined by inspiration or observation of models of existing products, various impressions from the real life, various visual references, a perception and an analysis of a collective experience or need.

The working methods can be approached individually or by creative teams and are based upon imagining and creation through drawing and graphic representations as well as upon the transposition of ideas in study models, aiming at defining the form as an expression of the concept formulated in the research and analysis steps.

As a development of the classical methods, new IT instruments are required, together with specific drawing, simulation, representation, environmental rendering and animation software, in order to define all detailed characteristics, aspects and variants

The practical content of this methodology can be made complete by taking into account the knowledge of the designer, the special requirements of the project and the complexity of the required object.

To structure and to use this kind of algorithms means to have a practical and efficient instrument for developing functional and compositional-constructive variants, which can be used especially in Step 5 .

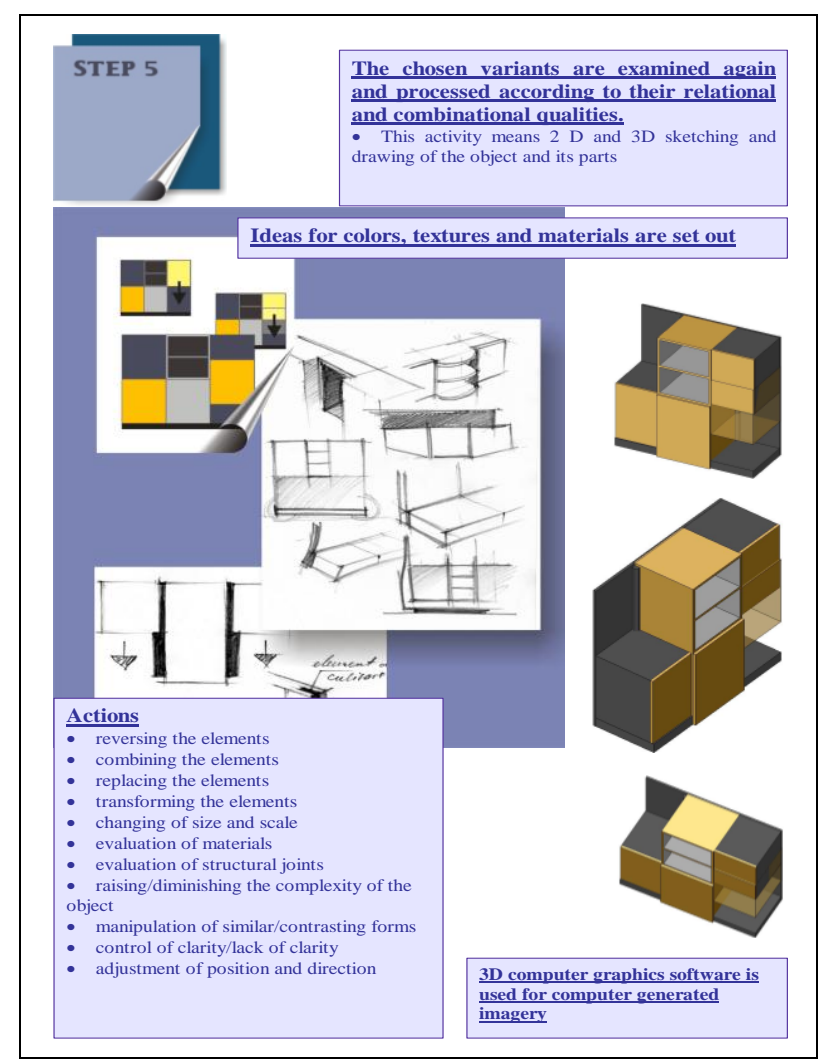

Fig. 4. Step 5 - Developing the concept

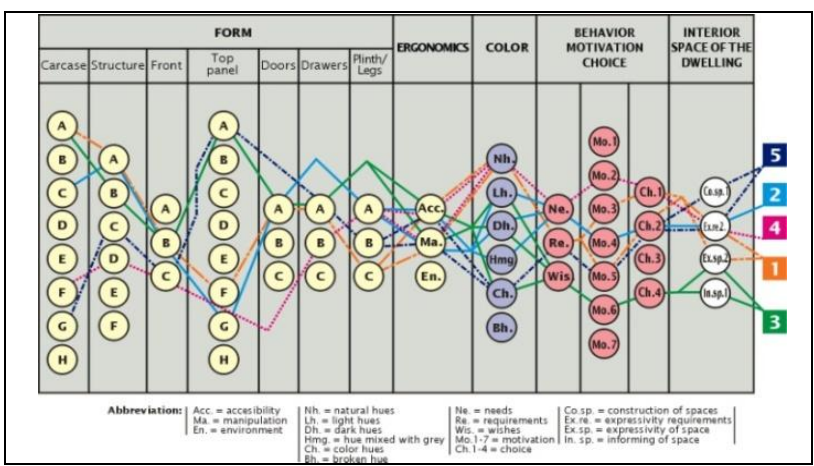

Fig. 5. The algorithms of modeling the form of furniture - an adequately applied instrument

\section{REFERENCES}

Burdek, E.; Bernhard. 1975. Einführung in die Designmethodologie. Band 2, Redaktion Designtheorie, Hamburg

Design \& Imitation, 2004. Industries Françaises de l'Ameublement, Media, ISBN 2-951-1868-9-4, Paris

Itten, J., 1975. Design and Form. The Basic Course at the Bauhaus and Later - revised Edition, John Wiley\&Sons Inc., ISBN 978-0-471-28930-2, Londra

Norbury, B., 2000. Furniture for the $21^{\text {st }}$ Century, Viking Studio, USA

Pearce P., Pearce S. 1980. Experiment in Form. A Foundation Course in Three-Dimensional Design, Van Nostrand Reinhold Company. ISBN 0-442-26497-6. New York 